\title{
A DEPENDÊNCIA ECONÔMICA BRASILEIRA: ENTRE O CASO DAS COMMODITIES, A FINANCEIRIZAÇÃO DO CAPITALISMO, A DESINDUSTRIALIZAÇÁO E A REPRIMARIZAÇÃO DA ECONOMIA
}

\author{
BRAZILIAN ECONOMIC DEPENDENCE: BETWEEN THE CASE \\ OF COMMODITIES, FINANCIALIZATION OF CAPITALISM, \\ DEINDUSTRIALIZATION AND THE REPRIMARIZATION OF THE \\ ECONOMY
}

Lucas Machado Fagundes ${ }^{\mathrm{I}}$ (1)
Emanuela Gava Caciatori ${ }^{\mathrm{II}}$ (1)

${ }^{\mathrm{I}}$ Universidade do Extremo Sul

Catarinense, Criciúma, SC, Brasil;

Universidad Autónoma de San Luis de

Potosí, Potosí, México; Universidade de Brasília, Brasília, DF, Brasil; Universidad de Buenos Aires, Buenos Aires, Argentina

II Universidad Autónoma de San Luis de Potosí, Potosí, México. Mestranda em Direitos Humanos. E-mail: emanuela gc@hotmail.com

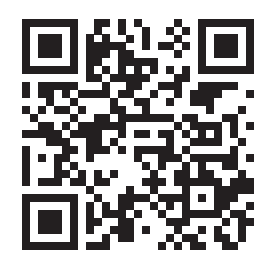

DOI: http://dx.doi.org/10.31512/rdj.v20i38.166

Autor convidado
Resumo: A temática do presente estudo é a questão da política econômica dependente do Estado brasileiro no contexto geopolítico da globocolonialidade. Assim, propóese contextualizar o cenário econômico local a partir da virada para o século XXI, pautando-se, para tanto, a influência do ciclo das commodities, problematizaçóes concernentes aos impactos da financeirização do capitalismo e as preocupaçóes quanto à desindustrialização e à reprimarizaçáo da economia brasileira. A hipótese é que a soberania econômica nacional é bloqueada pela privatizaçáo da esfera pública manifesta na política econômica no início do século; logo, a Teoria da Dependência irá servir de base interpretativa e reflexiva para atingir o objetivo de entender a maneira que o capitalismo global se relaciona com o capitalismo marginal, manifestando uma hegemonia política privatista. Para tal finalidade investigativa, este trabalho utilizou a metodologia dedutiva, em pesquisa do tipo teórica, com emprego de material bibliográfico diversificado, bem como se procedeu à utilização de índices econômicos oficiais. Portanto, aqui esta o resultado de uma reflexão provocativa sobre a postura da político-econômica brasileira no sentido da reprodução $\mathrm{da}$ dependência globocolonizada em detrimento do desenvolvimento econômico soberano.

Palavras-chave: Teoria da Dependência; Soberania econômica bloqueada; Politica econômica financeirizada; Globocolonialidade; Capitalismo marginal.

Abstract: The theme of the present study is the issue of economic policy dependent on the Brazilian state in the geopolitical context of globocoloniality. The proposal is to contextualize the local economic scenario from the turn to the 21 st century, based on the influence of the 
commodity boom, problematization concerning the impacts of the financialization of capitalism and concerns about deindustrialization and reprimarization of the Brazilian economy. The hypothesis is that national economic sovereignty is blocked by the privatization of the public sphere manifest in economic policy at the beginning of the century. Thus, the theory of dependence will serve as an interpretive and reflective basis for achieving the goal of understanding the way global capitalism relates to marginal capitalism, manifesting a privatist political hegemony. For this investigative purpose, this work used the deductive methodology, in theoretical research, using diverse bibliographic material, as well as the use of official economic indexes. Therefore, here is the result of a provocative reflection on the Brazilian politicaleconomic stance towards reproducing globalized dependence at the expense of sovereign economic development.

Keyword: Dependency theory; Economic sovereignty blocked; Financialized economic policy; Globocoloniality; Marginal capitalism.

\section{Introdução}

O tema do presente estudo é a questão da política econômica nacional no cenário da globocolonialidade como fenômeno transnacional de financeirização das relações sóciopolíticas, ou seja, de privatização do espaço público e diminuição da ingerência estatal nas questóes de soberania econômica, o que leva ao marco de referência da dependência e a reprodução de um padrão internacionalizado de poder hegemônico.

Logo, a delimitação da proposta da pesquisa se encontra na questão da postura do Estado brasileiro quanto as commodities, a financeirização e a desindustrialização como fenômenos econômicos de uma política nacional que atende ao capital financeiro internacional em detrimento das demandas internas, algo que será evidenciado no texto como manifesta soberania bloqueada.

Frente a isto, o problema central elencado na reflexão que segue trata da possibilidade de continuidade e atualidade da chamada Teoria da Dependência para interpretação da dominação econômica no cenário nacional ou regional. Entenda-se que a Teoria da Dependência pode, na atual conjuntura da política econômica (analisada nas primeiras décadas do século XXI) recuperar sua atualidade como marco referencial de leitura crítica da globalização financeira neoliberal.

Nesse sentido, a hipótese que se apresenta é que o país segue subordinado e dependente dos centros de poder mundial e dos organismos privados internacionais que passaram a ocupar um papel importante no espaço político decisório no contexto globocolonizado; e que a política econômica nacional no início do século XXI intensificou e tornou ainda mais saliente o fenômeno de dependência, evidenciando a direta 
subordinação do Brasil com o cenário internacional e os bloqueios ao desenvolvimento econômico nacional soberano.

A metodologia utilizada no presente trabalho foi a dedutiva, em pesquisa do tipo teórica, procedendo-se um levantamento de base conceitual e reflexiva da temática: priorizando assuntos como dependência, Estado, desenvolvimento econômico e globalização. Assim, foi utilizado material bibliográfico diversificado, especialmente livros e artigos de periódicos, bem como, para fins de análise do objeto, índices econômicos oficiais e reportagens jornalísticas, que noticiam o cenário global, nacional e mesmo regional.

A organização do texto obedece uma linha coerente em torno da contextualização do desenvolvimento da política econômica do Estado brasileiro, entendido este como forma de organização política que vem priorizando a dependência econômica na atual fase do capitalismo transnacionalizado; enfim, trata-se de uma proposta dividida em três partes, as quais têm como fio condutor a análise da conjuntura da política econômica do Estado nacional no início do século XXI (capturado por interesses do capital financeiro globalizado)

Por fim, a relevância do estudo se localiza no fato de permitir concluir que os índices econômicos são diretamente influenciados pelo cenário externo - o que se mostra ainda mais evidente no cenário da globalização -, de modo que a economia torna-se instável, no caso de não haver outra base capaz de solidificar os indicadores econômicos e blindar o país das constantes variações internacionais.

\section{0 cenário no campo econômico nacional no início do Século XXI: uma conjuntura dependente}

A partir dos anos 2000, o Brasil experienciou períodos de grande variação em termos de aceleração e desaceleração econômica. Especialmente no período compreendido entre 2004 e 2011, o país apresentou uma melhora exponencial nos índices econômicos, que passaram a decair no período subsequente (CARVALHO, 2018). O cenário internacional influenciou fortemente a flutuação dos indicadores econômicos do país.

A economista Laura Carvalho (2018) pontua que a alta demanda chinesa de commodities impactou de maneira positiva as economias latino-americanas no início do século XXI e que, da mesma maneira, o cenário externo desfavorável influenciou a baixa econômica vivenciada em seguida (CARVALHO, 2018, p. 13).

Especificamente, Laura Carvalho aponta que em 2004 e 2005 o crescimento da economia brasileira deu-se em razão de um boom de exportaçóes e que somente e a partir de 2006 é que é possível atribuir o bom desempenho econômico do país à política econômica interna (CARVALHO, 2018). Importa assinalar, contudo, que o 
desempenho econômico vivenciado pelo país no período analisado pela economista não foi acompanhado de crescimento industrial, ao contrário, teve como protagonista os setores de serviços. Ocorre que quando se tem um crescimento no setor do comércio que náo é acompanhado por crescimento industrial, significa que os produtos comercializados são importados, o que se verificou no Brasil, vez que "[...] o total de importações do país cresceu 103,4\% no acumulado entre o fim de 2005 e o fim de 2010, em termos reais" (CARVALHO, 2018, p. 43).

Esse mesmo período foi marcado pela valorização do real em relação ao dólar, o que favorece as importações e prejudica as exportaçóes, uma vez que os produtos importados tornam-se comparativamente mais baratos quando comparados aos produtos de produção nacional, é dizer, "[...] os produtos nacionais ficam mais caros em relação aos estrangeiros e a indústria doméstica perde participação no mercado externo (o que reduz as exportaçóes do país) e no mercado interno (pela compra maior de importados)" (CARVALHO, 2018, p. 44). A indústria nacional perdeu espaço, levando a uma série de economistas e analistas a se preocuparem com o tema da desindustrialização brasileira. Contudo, a exportação de commodities não foi prejudicada no período, especialmente devido à alta demanda de matéria-prima que a economia chinesa necessitava devido a sua dinamização.

Nesse sentido, Francisco de Oliveira aponta que, durante o governo Lula, a economia brasileira permaneceu dependente da expansão do mercado mundial, especialmente da economia da China, para vender as commodities. O autor acrescenta, ainda, que a política externa do governo, nesse período, exacerbou a característica do Brasil como produtor de commodities de baixo valor agregado, e não foi capaz de modificar a estrutura da economia interna (OLIVEIRA, 2018, p. 40).

A exportação de commodities - produtos agrícolas, minerais, gás, petróleo, etc. - corresponde a uma fatia considerável do PIB brasileiro (UNCTAD, 2017), de modo que torna a economia brasileira dependente de fatores externos do cenário internacional, como a mudança do preço das commodities e a situação econômica dos países importadores dos produtos brasileiros. É possível traçar um paralelo, pois, historicamente a economia do Estado brasileiro se alicerça na exportação de produtos primários - veja-se o ciclo do açúcar e do ouro (SCHWARCZ; STARLING, 2017), e atualmente vislumbra-se forte ênfase da economia brasileira na exportação de produtos como a soja, carnes e petróleo (UNCTAD, 2017), que demandam, via de regra, pequeno grau de industrializaçáo (SVAMPA, 2013).

Tal situação ocorre, muitas vezes, em detrimento do investimento no desenvolvimento de setores mais tecnológicos e estratégicos, capazes de solidificar mais estruturalmente e tornar menos instáveis os indicadores econômicos do país. 


\section{A manifesta continuidade da dependência político-econômica: o ciclo das Commodities}

A dependência do Estado brasileiro também se vislumbra na relação com as commodities, conforme dados expostos no relatório State of Commodities Dependence $2016^{1}$ (UNCTAD, 2017). Esse relatório aponta que, durante o biênio de 2014-2015, a exportaçáo de commodities gerou uma receita de 132 bilhóes, o que corresponde a 6,5\% do PIB do país, superando os 5,6\% do período de 2009-2010, anteriormente avaliado (UNCTAD, 2017).

Ademais, o relatório da Conferência das Nações Unidas sobre o Comércio e Desenvolvimento demonstra que o país que mais importa as commodities brasileiras é a China (UNCTAD, 2017), o que aponta para uma significativa mudança nas relaçóes comerciais internacionais que o Brasil mantêm, que outrora eram realizadas especialmente com os Estados Unidos e a União Europeia.

No caso brasileiro, de maneira específica, é possível observar que desde os primórdios da conquista, o país tem cumprido a função de exportador de matéria-prima para os centros do poder. Atualmente, passados 500 anos do início da colonização, a situação persiste ${ }^{2}$ : parte expressiva do saldo econômico do Brasil é oriundo da exportação de commodities, precisamente bens agrícolas e minerais (UNCTAD, 2017, p. 141). O relatório State of Commodities Dependence 2016 também revela que, apesar do aumento e da porcentagem expressiva do PIB, o Brasil ainda é o país menos dependente da exportação de commodities da América do Sul. Estima-se que 63\% de todas as mercadorias exportadas pelo país são commodities (apenas para fins comparativos, a cifra da Bolívia atinge 95\% e do Chile 86\%) (EXAME, 2017, on-line), sendo que a Conferência das Naçóes Unidas sobre Comércio e Desenvolvimento (UNCTAD) classifica um país como dependente de bens primários quando mais de $60 \%$ do saldo das mercadorias exportadas for referente à venda de commodities (ONU Brasil, 2017, on-line).

O relatório demonstrou que a economia brasileira, no período analisado, se tornou mais dependente da exportação de commodities, sendo que, do total de commodities exportado, $57 \%$ corresponde a itens alimentícios e $23 \%$ a minérios. No período anterior (2009-2010), 51\% representavam os itens alimentícios e 27\% os minérios (ONU Brasil, 2017, on-line), o que demonstra, também, uma modificação no peso de cada classe de commodities no PIB brasileiro.

1 Estado da Dependência das Commodities 2016, em tradução de livre autoria.

2 Evidente que tal afirmação não desconsidera o parque industrial que o país possui e a diversificação existente das atividades econômicas. No entanto, conforme se demonstrou no capítulo 2 , há uma séria preocupação com a tendência de desindustrialização e reprimarização das economias latino-americanas, incluindo-se nisso o Brasil, em que pese seja um dos países da região com mais bem sucedida industrialização. 
Contudo, não se propõe, aqui, tecer críticas de maneira rasa ao setor primário brasileiro e à exportação de commodities, pois é compreendida a importância do setor para a economia do país, entendendo-se que "[...] talvez o principal motor do crescimento [econômico] nos anos 2000 tenha sido o aumento da demanda pelos produtos que exportamos, em grande parte resultado do desempenho excepcional da economia chinesa” (CARVALHO, 2018, p. 146). Assinala-se, entretanto, que não necessariamente o que faz com que a economia cresça é capaz de acarretar melhoras nas condiçóes de vida e trazer benefícios à população como um todo, em outras palavras, não é porque o bolo cresce que ele necessariamente será dividido de maneira mais igualitária.

Não obstante essa constatação, Laura Carvalho agrega que diversos economistas, ante a falta de competitividade da indústria nacional, apontaram que o caminho que o Brasil devia trilhar seria o de centrar seu desenvolvimento industrial com ainda mais destaque para as exportaçóes, nos moldes dos países asiáticos (CARVALHO, 2018).

Contudo, a economista pontua que para que o Brasil pudesse desenvolver novos setores exportadores e competir com os países asiáticos na indústria manufatureira, por exemplo, teria que proceder uma longa e duradora desvalorização do real, o que perpassaria também por reduçóes de salários dos trabalhadores, que seriam possivelmente incompatíveis com o próprio regime democrático (CARVALHO, 2018) e acrescenta-se, incompatível também com a perspectiva dos direitos sociais dos trabalhadores. É dizer, competitividade no mercado internacional e elevação do PIB não significa, necessariamente, redução de desigualdade social e elevação de indicadores socioeconômicos do país; é bem sabido que o capitalismo pode confortavelmente combinar, como uma das contradiçóes inerentes ao sistema, crescimento econômico e aumento da pauperizaçáo da população.

Nesse viés, prescreve Laura Carvalho:

Sendo o Brasil um país continental e desigual, com grande potencial de expansão de mercado interno, adaptar para cá o modelo de crescimento liderado por exportaçóes adotado em tantos países asiáticos não parece a melhor estratégia. Afinal, para competir com esses países no mercado internacional de manufaturados pouco sofisticados, seria necessária uma desvalorização muito grande do real e, consequentemente, uma redução substancial no poder de compra de nossos salários. Como vimos, desvalorizaçóes do real encarecem produtos importados e são inflacionárias, reduzindo salários reais. [...] A melhor opção parece ser, portanto, o fortalecimento do mercado interno com base nos pilares da distribuiçáo de renda e dos investimentos em infraestrutura física e social. (CARVALHO, 2018, p. 178)

No que concerne à exportação específica de commodities, urge pensar a dependência que acarreta tal à economia brasileira, já que os índices econômicos do país são diretamente influenciados pelo bom ou mau desempenho dos países cuja venda das commodities é destinada. Nesse sentido, ao analisar a economia brasileira entre os anos 2000-2016, a economista Laura Carvalho conclui que, “[...] também ficou claro que o modelo baseado na exportação de commodities e de produtos agroindustriais, além do 
enorme custo ambiental, deixa o país refém da conjuntura internacional e de preços demasiadamente voláteis" (2018, p. 178).

A persistência de aposta centrada num setor exportador obstaculiza reais possibilidades de um desenvolvimento autônomo e estável. Sem embargo, Laura Carvalho (2018) aponta que a saída perpassa necessariamente pela aposta em uma política tecnológica estratégica.

No entanto, tampouco se trata de simplesmente investir em setores produtivos para competir livremente com o mercado internacional, vez que há de ser considerada a realidade brasileira de desigualdade social, e a competitividade no plano internacional, por si, não traz qualquer garantia de desenvolvimento e melhora nas condiçóes de vida da população. Em entrevista concedida ao El País, a mesma economista afirma que a redistribuição de renda é ponto fulcral para solucionar o problema socioeconômico brasileiro:

O Brasil é um país com a renda mal distribuída, mas que tem uma renda média muito mais alta que países asiáticos que hoje exportam produtos manufaturados simples. Se você quiser competir com esses países, você teria que levar o preço do dólar em reais a um patamar tão alto que na prática isso significaria aumentar o custo de vida dos brasileiros, reduzir o salário real. Não é a China, é Bangladesh. Esse ideal de modelo de desenvolvimento, de querer ficar competitivo lá fora para gerar uma indústria que vai nascer e vai ser pujante, eu tendo a achar que vai ser um tiro no pé. Você pode acabar matando algo que é muito mais importante para a gente que é nosso mercado interno. Para o nosso mercado interno crescer e se desenvolver, é melhor uma estratégia de redistribuição da renda, com aumento e crescimento dos salários, com efeitos dinâmicos que isso gera. (2018b, on-line)

Além disso, para evitar a continuidade da vulnerabilidade econômica perante o plano internacional, também se faz necessária a diversificação da estrutura produtiva (CARVALHO, 2018b, on-line), já que a dependência se intensifica na medida em que a econômica circunde a poucos setores. A economista defende que a melhor maneira de evitar a influência de grupos de grande poder econômico e a captura do Estado pelos interesses do capital é o investimento em uma política tecnológica estratégica (CARVALHO, 2018) e que a sustentabilidade, no contexto do século XXI, deve ser o eixo central de qualquer política que incentive novos setores e novas tecnologias.

$\mathrm{O}$ argentino Claudio Katz discute a questão pelo viés do impacto na economia interna dos países do continente, que a manutenção de um ciclo econômico embasada em um modelo de extrativismo exportador implica:

A tecnificação e a capitalização da agricultura introduziram importantes mudanças na economia latino-americana. O agronegócio fortaleceu a gravitação das lavouras orientadas pela demanda externa, em detrimento da oferta local. [...] Esse modelo de extrativismo exportador reforça a preeminência das atividades primárias, em detrimento da produção industrial voltada para o mercado interno. [...] O modelo atual enfatiza a vinculação de todas as economias à flutuação internacional dos preços das commodities e 
torna o nível de atividade mais volátil. O PIB da Argentina, por exemplo, se contraiu e expandiu significativamente 12 vezes nos últimos trinta e cinco anos. A mesma oscilação no Brasil apresentou menor intensidade. (KATZ, 2018, pp. 315-316). ${ }^{3}$

Ademais, também é de grande importância ploblematizar o modelo extrativista exportador desde a perspectiva socioambiental, uma vez que esse modelo, para além de implicar em uma reprimarização das economias latino-americanas (SVAMPA, 2012, p. 17), traz consequências ambientais e desencadeia conflitos socioambientais. Maristella Svampa prescreve que "[...] os conflitos socioambientais tendem a se combinar perversamente com uma tipologia inerente ao modelo extrativista ${ }^{4 ”}$ (2012, p. 21).

Esta autora argentina mencionada no parágrafo anterior, alcunha o período de alta na exportação de bens primários latino-americanos como "Consenso das Commodities", e sustenta que esse processo ocorreu devido ao boom do preço internacional dessa classe de produtos (2013, p. 31). A autora descreve o processo como dual, na medida em que, ao mesmo tempo em que gera crescimento econômico e aumenta as reservas internacionais dos países latino-americanos, aprofunda as desigualdades sociais e gera novas assimetrias nas sociedades da região (SVAMPA, 2013).

Em igual sentido, descreve que o "Consenso das Commodities" produziu novas formas de dependência e dominação e ensejou um processo de reprimarização nas economias nuestroamericanas, pois reorientou as atividades econômicas da regiáo à produção de matérias-primas de baixo valor agregado (SVAMPA, 2013). Svampa vai além e afirma que esse ciclo de exportação é associado a uma lógica neocolonial, de modo similar ao ocorrido no passado em nossas sociedades, que produz "[...] forte fragmentação social e regional e configuram espaços sócio-produtivos dependentes do mercado internacional" (SVAMPA, 2013, p. 35)

A autora aponta que há um núcleo duro que aproxima a lógica do Consenso de Washington com o "Consenso das Commodities", consistente na aceitação do lugar reservado à América Latina na divisão internacional do trabalho. Nesse sentido, prescreve:

Em nome das "vantagens comparativas" ou da pura subordinação à ordem geopolítica mundial, conforme seja o caso, os governos progressistas, assim como os mais

3 [texto original]: La tecnificación y capitalización del agro han introducido importantes cambios en la economía latinoamericana. El agrobusiness reforzó la gravitación de los cultivos orientados por la demanda externa en desmedro del abastecimiento local. [...] Ese modelo de extractivismo exportador refuerza la preeminencia de las actividades primarias, a costa de la producción manufacturera centrada en el mercado interno. [...] El modelo actual acentúa la atadura de todas las economías al vaivén internacional de precios de las materias primas y torna más volátil el nivel de actividad. El PIB de Argentina, por ejemplo, se contrajo y expandió significativamente en 12 oportunidades en los últimos treinta y cinco ańos. El mismo vaivén presentó en Brasil una intensidad inferior. (KATZ, 2018, p. 315-316, tradução de livre autoria)

4 [texto original]: "[...] los conflictos socioambientales suelen combinarse perversamente con una tipología inherente al modelo extractivo" (SVAMPA, 2012, p. 21, tradução de livre autoria).

5 [texto original]: "[...] fuerte fragmentación social y regional y van configurando espacios socioproductivos dependientes del mercado internacional. (SVAMPA, 2013, p. 35, tradução de livre autoria). 
conservadores, tendem a aceitar como "destino" o novo "Consenso das Commodities", que historicamente reservou para a América Latina o papel de exportadora da natureza, minimizando as enormes consequências ambientais, os efeitos socioeconômicos (os novos quadros de dependência e a consolidação dos enclaves exportadores) e sua tradução política (disciplina e formas de coerção sobre a população). (SVAMPA, 2013, p. 37) ${ }^{6}$

É dizer, é urgente repensar a perpetuação de um modelo econômico que, para além de manter os países submissos e vinculados às oscilaçóes do mercado internacional financeirizado, ocasiona significativos impactos em termos ambientais e ecológicos, uma vez que se funda numa política extrativista, o que permite a continuidade da dependência, por meio da contínua e constante exploração das riquezas naturais dos países, que são tratadas meramente como matérias-prima e vendidas como commodities aos mercados consumidores.

\section{Os reflexos da dependência político-econômica no capitalismo marginal: desindustrializaçáo e financeirização da esfera pública.}

Seguindo o desenvolvimento da questão da dependência econômica, torna-se imperioso também tecer algumas consideraçóes quanto ao tema da desindustrialização latino-americana e brasileira, especialmente. O economista Luiz Carlos Bresser-Pereira, em artigo publicado na edição digital da Folha de São Paulo, em 2010, enfatiza que o Brasil vive um processo de desindustrialização, apontando a redução da fatia do PIB correspondente à indústria. Assinala Bresser-Pereira que “[...] no final dos anos 1940, a indústria representava 20\% do PIB brasileiro, em 1985 chegou a 36\%, em 2008 havia baixado para 16\%" (2010, on-line) e que "[...] nossa desindustrialização é para produzir mais commodities" (2010, on-line). O economista estabelece uma ligaçáo direta entre a exportação de commodities, a reprimarização das economias, a desindustrialização e a adoção das diretrizes liberalizantes do Consenso de Washington, e defende que o Brasil começou a desindustrializar-se em 1992, após proceder à abertura financeira, o que prejudicou a indústria nacional (BRESSER-PEREIRA, 2010, on-line).

O cenário se replica na regiáo da América Latina como um todo, sendo que Cláudio Katz traz o dado de que a participação da indústria no PIB latino-americano caiu de 12,7\% (1970-1974) para 6,4\% (2000-2006) (KATZ, 2018, p. 314). Especificamente

6 [texto original]: "En nombre de las «ventajas comparativas» o de la pura subor-dinación al orden geopolítico mundial, se-gún los casos, los gobiernos progresistas, así como aquellos más conservadores, tienden a aceptar como «destino" el nuevo "Consenso de los Commodities», que históricamente ha reservado a América Latina el rol de ex-portador de naturaleza, minimizando las enormes consecuencias ambientales, los efectos socioeconómicos (los nuevos marcos de la dependencia y la consolidación de enclaves de exportación) y su traducción política (disciplinamiento y formas de coerción sobre la población).” (SVAMPA, 2013, p. 37, tradução de livre autoria). 
tratando do caso brasileiro, Katz assinala que “[...] o aparato industrial perdeu a dimensão alcançada nos anos oitenta. A produtividade estagna, o déficit externo se expande e os custos aumentam com a deterioração da infraestrutura de energia e transporte" (2018, p. $314)^{7}$, o que, para o autor, se deve a diminuição de exportações de média e alta tecnologia. É dizer, o processo de desindustrialização reforça a reprimarização da economia, de modo que se diminui as produçóes e exportaçóes de produtos de maior valor agregado, ao passo em que se aumenta a produção de commodities. Ademais, o argentino também pontua que a regressão industrial acarreta o empobrecimento da população e, consequentemente, o aumento da concentração de renda e da desigualdade social, uma vez que se compensa a perda dos postos de trabalho industriais por empregos informais (KATZ, 2018) e, portanto, mais precários.

No mesmo sentido, Carlos Eduardo Martins também pontua a contração do PIB latino-americano na fatia correspondente à indústria durante os anos 2000, ainda que a região tenha apresentado acelerado crescimento econômico no mesmo período (MARTINS, 2011). O autor prescreve que a diminuição da produção manufatureira no PIB da América Latina tem resultados mais dramáticos no Brasil e na Argentina (MARTINS, 2011) e assinala o "[...] papel mais limitado que o setor industrial passa a ter na América Latina e o protagonismo do capital financeiro” (MARTINS, 2011, p. 334).

No que tange à pauta exportadora latino-americana, verifica-se uma "[...] forte queda das exportações de manufaturados: entre 2001 e 2009, essas exportaçóes caem de $58,9 \%$ para $47,1 \%$ do total. No mesmo período, elevam-se fortemente as de produtos primários, que passam de 41,1\% para 52,9\% do total" (MARTINS, 2011, p. 334-335). Há, portanto, uma evidente relação entre a reprimarização, a desindustrialização e a preponderância do capital financeiro, processos estes que se entrelaçam na região. Nesse sentido, sentencia Martins:

O neoliberalismo aprofunda ainda mais as assimetrias tecnológicas internacionais e reprimariza a pauta exportadora dos países dependentes, vinculando seus saldos comerciais a produtos de origem agrícola ou mineral, estabelecendo um modelo ecologicamente devastador. (MARTINS, 2011, p. 340)

Seguindo a mesma lógica, Katz estabelece uma relação entre a volatilidade econômica enfrentada nos países da região, como consequência da manutenção, por parte dos governos de cunho progressista que se elegem na América Latina após experiências neoliberais, de uma política baseada em uma lógica exportadora, modelo este incapaz de promover mudanças estruturais e que mantêm os países completamente dependentes do cenário internacional (KATZ, 2018). Cabe destacar que:

7 [texto original]: “[...] el aparato industrial ha perdido la dimensión alcanzada en los años ochenta. La productividad se estanca, el défict externo se expande y los costos aumentan con el deterioro de la infraestructura de energía y transporte." (KATZ, 2018, p. 314, tradução de livre autoria). 
[...] essa política não tentou erradicar o esquema de exportação agro-mineiro. Buscou alianças com os protagonistas desse modelo, rejeitou parcialmente o protecionismo e fortaleceu os laços com as corporaçóes transnacionais. Com esse perfil conservador, priorizou a política macroeconômica e omitiu as transformaçóes estruturais (Katz, 2016). No entanto, voltou a depender da situação internacional e apenas houve bonança enquanto a valorização das matérias-primas prevaleceu. $\mathrm{Na}$ fase favorável, a dívida foi reduzida, um certo superávit comercial surgiu e a indústria foi parcialmente recomposta. O crescimento foi sustentado com o influxo de dólares. Como as fundaçóes do subdesenvolvimento permaneceram intactas, com o fim das vacas gordas, recriou-se a crise. (KATZ, 2018, p.318). ${ }^{8}$

Ainda nesse viés, Francisco de Oliveira, analisando o cenário de exportação de commodities e o crescimento econômico experienciado pelo Brasil durante o governo Lula, assinala que os bens primários voltaram a liderar as exportaçóes, o que não ocorria desde 1978. Vale mencionar as palavras deste saudoso autor:

O crescimento se baseia numa volta à "vocação agrícola" do país, sustentado por exportaçôes de commodities agropecuárias - o Brasil, país de famintos, é hoje o maior exportador mundial de carne bovina - e minério de ferro, graças às pesadas importaçóes da China. Com o simples arrefecimento do crescimento chinês, que de 10\% ao ano regrediu a uns $8 \%$, a queda das exportações brasileiras já provocou forte retração do PIB agropecuário. As exportaçóes voltaram a ser lideradas pelos bens primários, o que não acontecia desde 1978. (OLIVEIRA, 2018, p. 128).

$\mathrm{Na}$ América Latina, os Estados nunca atingiram uma independência fática, isto é, mesmo com o fim do colonialismo enquanto sistema formal e direto de dominação, houve a perpetuação de práticas exploratórias e que reproduzem mecanismos que geram desigualdade social. Sem embargo, essas práticas subsistem, pois são orientados por interesses privados das elites nacionais, no plano interno, e no plano externo, por interesses do capital internacional, ainda que mantenham em condição de subjugamento as populações latino-americanas. Conforme recorda Gilberto Bercovici, a soberania é bloqueada, no contexto dos Estados periféricos "[...] tanto por fatores externos como pelo poder privado e pelo poder econômico internos" (BERCOVICI, 2004, p. 271-272).

Nesse trabalho, propóe-se que o fenômeno da dependência e a colonialidade do poder bloqueiam a soberania dos Estados periféricos, o que coloca óbice a um desenvolvimento autônomo da região latino-americana, seja em sua acepção econômica, política, cultural ou social. Tal assertiva se verifica também no cenário atual de financeirização do capitalismo, momento em que a soberania dos Estados periféricos

8 [texto original]: “[...] esa política no intentó erradicar el esquema agrominero exportador. Buscó alianzas con los protagonistas de ese modelo, rechazó parcialmente el proteccionismo y estrechó vínculos con las empresas transnacionales. Con ese perfil conservador priorizó la política macroeconómica y omitió las transformaciones estructurales (Katz, 2016). No obstante ese ensayo volvió a depender de la coyuntura internacional y solo hubo bonanza mientras prevaleció la valorización de las materias primas. En la fase favorable se redujo el endeudamiento, emergió cierto superávit comercial y se recompuso parcialmente la industria. El crecimiento se costuvo con la afluencia de dólares. Como los cimientos del subdesarrollo permanecieron intactos, el fin de las vacas gordas recreó la crisis." (KATZ, 2018, p. 318, tradução de livre autoria). 
é bloqueada não somente por outros Estados, como na antiga sistemática de colôniametrópole, mas também por outros atores, no plano nacional e internacional, como empresas transnacionais, e organismos financeiros como o FMI e o Banco Mundial. Esses organismos impõem agendas políticas e econômicas aos países, exercendo, desta forma, dominação fática.

O sociólogo mexicano Pablo González Casanova sustenta que “[...] na etapa histórica da transnacionalização a dependência se reformula de uma maneira institucional, através do fenômeno bem conhecido da dívida externa” (1995, p. 57), isto é, o fenômeno da dívida externa é a institucionalização da dependência, pois, junto com os empréstimos, os organismos como FMI ditam agendas, impóe sançóes e dão continuidade ao nexo colonial de dependência.

Se o Fundo Monetário Internacional é dominado pelos países ricos e pela banca internacional, os empréstimos que outorga e a política econômica que impóe não servem apenas para aumentar a riqueza dos grupos privilegiados dos países prestamistas e da banca que os domina. Servem também para aumentar a dominação desses países e dessa banca sobre os países pobres e seus sistemas financeiros e bancários, produtivos e mercantis, de transportes e serviços. Se a dominação creditícia contribui para aumentar utilidades e transferências, e também para adquirir como pagamento novos ativos, propriedades, recursos naturais e territórios, não há dúvida de que também é útil para aumentar a dominação dos governos e dos empresários endividados. A dominação se torna regular e constante. [...] O vencimento periódico da dívida externa converte a dependência em um fenômeno articulado e permanente. Os credores organizam a dominação do conjunto das economias, dos governos, e das políticas sociais e culturais em torno do pagamento da dívida. Os períodos relativamente curtos para o acerto de contas, lhes permite uma articulação constante e institucional. De fato, a dívida externa corresponde a um complexo de mediação e dominaçáo que aciona de forma regular as demais estruturas de dependência. (GONZÁLEZ CASANOVA, 1995, p. 59-60)

A dependência também se vislumbra no cenário do século XXI, inclusive com a persistência da problemática da dívida pública em todo cenário latino-americano. No entanto, apesar de extremamente pertinente, pouco é debatido sobre a dívida pública e o peso que o pagamento de juros sobre os títulos da dívida pública tem no orçamento do Estado brasileiro9, por exemplo. Tal discussão é convenientemente ocultada, “[...] isso sem contar o fato de que ninguém no Brasil sabe de onde efetivamente essa dívida pública provém. Jamais foi realizada uma auditoria na dívida pública.” (SOUZA, 2017, p. 164).

Finalmente, imprescindível para a temática do trabalho é a abordagem e reflexão sobre o capitalismo em sua forma financeirizada. Nesse sentido, Francisco de Oliveira descreve que a financeirização do capitalismo acarretou à transferência da lógica do

9 A dívida pública bruta correspondia a 53,8\% do PIB em 2012, caindo para 51,7\% em 2013 e tornando a subir para 57,2\% em 2014 (CARVALHO, 2018, p. 90-95). Além disso, a dívida líquida possui ainda mais volatilidade, pois "desconta as reservas internacionais acumuladas pelo Banco Central. [...] quando o dólar sobe, a dívida líquida cai. E quando o dólar cai, a dívida líquida sobe.” (CARVALHO, 2018, p. 91) 
desenvolvimento para o cenário externo (OLIVEIRA, 2018). Sob outra perspectiva, para referir-se ao capitalismo financeirizado, o economista brasileiro Ladislau Dowbor (2018) utiliza a nomenclatura da "era do capital improdutivo". Nessa fase do capitalismo, a tendência é que a especulação financeira seja preponderante aos setores produtivos da economia (DOWBOR, 2018) e que ocorra, inclusive, "[...] o desvio dos recursos das atividades produtivas para atividades especulativas" (DOWBOR, 2018, p. 229), prova disso é os bancos e intermediários financeiros aumentarem seus já exorbitantes lucros mesmo em momentos de crise e recessão econômica (DOWBOR, 2018).

Para Dowbor (2018), o setor financeiro atua em forma de oligopólio, em redes de empresas transnacionais, o que lhe confere gigantesco e concentrado poder político, econômico e cultural. Logo, o grande objetivo, mais do que nunca, é o do lucro pelo lucro, o de gerar rentabilidade financeira a qualquer que seja o custo (DOWBOR, 2018).

Nesse sentido, o economista destaca a dimensão política que se vislumbra no sistema financeiro, uma vez que se verifica que “[...] os Estados, devido ao endividamento público com gigantes privados, viraram reféns e tornaram-se incapazes de regular este setor financeiro em favor dos interesses da sociedade" (DOWBOR, 2018, p. 78). A dificuldade de os governos enfrentarem os interesses corporativos e dos oligopólios para elaborarem políticas monetárias e financeiras que visem e fomentem o desenvolvimento da sociedade como um todo se verifica em todos os Estados (DOWBOR, 2018), contudo, impacta de forma ainda mais evidente as naçóes dependentes.

Nesse sentido:

Os governos passam, assim, a enfrentar resistências poderosas e articuladas quando tentam fomentar a economia. Recuperar a "confiança" do "mercado" não significa mais gerar melhores condições de produção, mas melhores condições de rentabilidade das aplicaçóes financeiras. A produção, o emprego, o desenvolvimento sustentável e o bem-estar das famílias não estão no horizonte das decisóes. [...] cada vez mais, o governo tem de prestar contas ao "mercado", e virar as costas para a cidadania. Com isto, passa a prevalecer, para a sobrevivência de um governo, não quanto ele responde aos interesses da população que o elegeu, e sim se o mercado, ou seja, essencialmente os interesses financeiros, se sentem suficientemente satisfeitos para declará-lo "confiável". (DOWBOR, 2018, p. 130-133).

Especificamente no caso brasileiro, a desregulação do sistema financeiro é inconteste, mormente quando se tem, no plano constitucional, a Emenda Constitucional de no 40/2003, que alterou o artigo 192 da Constituição Federal de 1988 e revogou os parágrafos que regulavam o sistema financeiro nacional e limitavam a taxa de juros reais a $12 \%$ ao ano. Hoje, na prática, não há qualquer limitação às taxas de juros praticadas pelas agências bancárias e financeiras. A proposta de emenda constitucional data de 1999, mesmo ano em que foi revogada, nos Estados Unidos, a Lei Glass-Steagall, que regulava o sistema financeiro (DOWBOR, 2018); o que demonstra que as distorçóes desse sistema 
não são exclusividade brasileira, ainda que aqui elas se vislumbrem com lente de aumento (DOWBOR, 2018), ante a condição de dependência e subdesenvolvimento.

Em relatório publicado pela Associação Nacional de Executivos de Finanças, Administração e Contabilidade (ANEFAC), datado de 2018, em estudo sobre as taxas de juros praticadas, a entidade explicita que “[...] as taxas de juros são livres e as mesmas são estipuladas pela própria instituição financeira não existindo assim qualquer controle de preços ou tetos pelos valores cobrados" (2018, p. 9). Essa total liberdade advém da revogação do artigo constitucional que regulava o sistema financeiro nacional. As taxas de juros praticadas no Brasil são altíssimas se comparadas às de outros países ${ }^{10}$, o que leva ao endividamento da população.

No Brasil, consequência da desregulação do sistema financeiro é, na prática, que "[...] a liberdade dos bancos de cobrar o que querem no Brasil faz com que a lógica financeira absorva, numa dinâmica deformada especulativa, qualquer subsídio, isenção, transferência ou outro privilégio concedido às empresas produtivas" (DOWBOR, 2018, p. 178). Com altas taxas de juros, o rentismo e a especulação se tornam mais lucrativos do que qualquer atividade produtiva. Evidente que há muito mais custos envolvidos na produção - que é o que gera empregos e movimenta a economia de forma geral - do que em aplicaçóes financeiras, que se traduzem em ganhos improdutivos, na medida em que trazem lucro somente para os acionistas.

Assim prescreve Dowbor:

Não há como escapar de uma realidade simples: abrir uma empresa, contratar trabalhadores, produzir e pagar impostos é muito mais trabalhoso do que aplicar em papéis da dívida pública, mas é o que estimula a economia. Quando você compra papéis, eles podem render, mas você não produziu nada, apenas gerou rendimentos sem contrapartida e, a partir de certo nível, isso se torna um peso morto sobre as atividades econômicas em geral. (DOWBOR, 2018, p. 155)

No mesmo sentido, Dowbor pontua que o sistema financeiro, nos moldes de distorção que hoje vigoram, aprofunda a desigualdade, na medida em que drena os recursos do sistema produtivo para o especulativo. É dizer, "[...] o sistema financeiro gera a apropriaçáo dos recursos náo por quem produz, mas por quem maneja papéis, o que por sua vez aprofunda a desigualdade, pois os aplicadores financeiros estão na parte superior de riqueza" (DOWBOR, 2018, p. 172). O atual sistema financeiro, que funciona de maneira desregulada, acaba por realizar uma distribuiçáo de renda para a parte mais rica da população, uma vez que, seja por meio dos juros sobre a dívida pública, seja por meio

10 Dowbor compara as taxas de juro praticadas no Brasil pelo banco Santander com as praticadas pelo Santander na Espanha, matriz do banco. Por exemplo, um empréstimo que no Brasil tem juro de 125,02\% ao ano, na Espanha teria juros na ordem de 3,5\%. Os juros de cheque especial e cartão de crédito são ainda mais altos. (DOWBOR, 2018, p. 201-202). Para informaçóes mais detalhadas sobre as taxas de juros praticadas no Brasil, buscar o capítulo 12 do livro de Ladislau Dowbor: "A dimensão brasileira: os quatro motores da economia" (DOWBOR, 2018). 
dos juros que encarecem o consumo e levam ao endividamento da população, ocorre a "[...] extração de uma parte do excedente socialmente produzido por quem se limitou a controlar e exigir o rendimento dos seus papéis" (DOWBOR, 2018, p. 183).

No entanto, ainda mais importante para este trabalho é abordar de que maneira o sistema financeiro exerce controle sobre as commodities. Na mesma linha, o economista afirma que "[...] produzir rende pouco. O que rende é intermediar a produção dos outros" (DOWBOR, 2018, p. 95) e que os intermediários da produção são, de maneira cada vez mais evidente, oligopólios que funcionam em formato de rede e ditam os preços finais dos produtos (DOWBOR, 2018).

A análise do economista até aqui privilegiado conduz à temática concernente à formação dos preços de cada produto, pontuando que vai muito além da mera medição da inflação (é preciso também investigar como ela é gerada e se há intencionalidade política - e de quem - nisso), expondo que não há informação apropriada sobre a formação da precificação dos produtos (DOWBOR, 2018).

Neste cenário, em que são formados verdadeiros oligopólios corporativos financeiros, a volatilidade dos preços é ditada por este segmento, e torna-se estrutural; especialmente a oscilação do preço do petróleo possui conexão direta com o poder corporativo (DOWBOR, 2018).

Denomina-se de commodity traders o setor financeiro que possui ingerência nos mecanismos de precificação desta classe de produtos. Nesse ponto, cita-se o estudo realizado por Joshua Schneyer, que relaciona o período de boom das commodities com a rentabilidade do sistema financeiro, explicitando de que maneira formam-se os preços das commodities no contexto que vigora:

Para o pequeno clube de companhias que comercializam alimentos, combustíveis e metais que fazem o mundo funcionar, a última década tem sido sensacional. Estimulado pela ascensão do Brasil, da China e da Índia e outras economias em rápida expansão, o global boom de commodities turbinou os lucros nas maiores empresas de especulaçáo. Elas formam um grupo exclusivo, cujos membros pouco regulados estão frequentemente baseados em paraísos fiscais como a Suíça. Juntos, valem mais de um trilhão de dólares em entradas anuais e controlam mais da metade das commodities livremente comercializadas. As cinco maiores renderam 629 bilhóes de dólares no ano passado, logo abaixo das cinco maiores corporaçóes financeiras e mais do que as vendas agregadas dos principais players de tecnologia ou telecomunicaçôes. Muitas acumulam posiçóes especulativas valendo bilhóes em matérias primas, ou estocam commodities em depósitos ou supertanqueiros durante períodos de oferta fraca. [...] Com suas conexôes e conhecimento interno - os mercados de commodities estão, na maior parte, livres de restriçôes de negociação com informaçóes privilegiadas -, os traders tornaram-se agentes de poder, especialmente na Ásia, América Latina e África, economias em rápido desenvolvimento. (SCHNEYER, $2011)^{11}$

11 [texto original]: "For the small club of companies who trade the food, fuels and metals that keep the world running, the last decade has been sensational. Driven by the rise of Brazil, China, India and other fast-growing economies, the global commodities boom has turbocharged profits at the world's biggest trading houses. They 
A formação do preço das commodities hoje apoia-se muito mais na voluntariedade dos grupos que comandam o sistema (os commodity traders) do que na lógica de oferta e demanda. Um pequeno número de companhias (dezesseis grupos) oligopolizam o comércio de commodities (DOWBOR, 2018) e são capazes, devido ao poder econômico - possuem capital trilionário - e político que gozam, de ditar as oscilaçóes nos preços das commodities, o que impacta de maneira muito direta e evidente a sociedade, especialmente os países que dependem da produção e exportação dessa classe de produtos.

Diante disso, a perspectiva da linha teórica seguida neste trabalho aponta que:

A visão que temos, em grande parte fruto dos comentários desinformados ou interessados na imprensa econômica, é que as flutuaçôes de preços das commodities resultam das variaçốes da oferta e da demanda. Ou seja, mecanismos de mercado. Na realidade não se pode imaginar que uma commodity com níveis tâo amplos e equilibrados de produçáo e consumo como o petróleo sofra variaçóes entre 17 e 148 dólares o barril em poucos anos, quando se trata sempre dos mesmos 95-100 milhões de barris diários, com variaçóes mínimas. É um comércio que lida com bens vitais para a economia mundial, mas cujos preços e fluxos resultam essencialmente de mecanismos de especulação econômica e de poder político. [...] O fato é que um conjunto de produtos que constituem o "sangue" da economia, como alimentos, minérios e energia, não são regulados nem por regras, nem por mecanismos de mercado. E muito menos por qualquer sistema de planejamento que pensa os problemas de esgotamento de recursos ou de impactos ambientais. A regulaçáo formal, por leis, acordos e semelhantes, não se dá antes de tudo porque se trata de um mercado mundial e não existe um governo mundial. Os países finalmente não tem como enfrentar o processo (DOWBOR, 2018, p. 101).

A problemática reside no ponto em que países e populações inteiras são atingidas por mecanismos de corporaçóes que não são democráticos, pois visam somente a lucratividade dos acionistas, sob o qual não exercem qualquer tipo de controle e que são convenientemente invisibilizados, ocultos e anônimos. Os intermediadores financeiros, via de regra, pouco estão interessados nos produtos em si sob o qual especulam, mas sim nas flutuaçóes do mercado e no lucro que podem obter no menor espaço de tempo (DOWBOR, 2018).

Dessa maneira, a produção e o consumo das commodities tem se mantido bastante estável nos últimos anos, não obstante a volatilidade dos preços seja altíssima, o que "[...] atinge diretamente tanto produtores quanto consumidores de commodities, ao gerar uma

form an exclusive group, whose loosely regulated members are often based in such tax havens as Switzerland. Together, they are worth over a trillion dollars in annual revenue and control more than half the world's freely traded commodities. The top five piled up $\$ 629$ billion in revenues last year, just below the global top five financial companies and more than the combined sales of leading players in tech or telecoms. Many amass speculative positions worth billions in raw goods, or hoard commodities in warehouses and super-tankers during periods of tight supply. [...] Their reach is expanding. Big trading firms now own a growing number of the mines that produce many of our commodities, the ships and pipelines that carry them, and the warehouses, silos and ports where they are stored. With their connections and inside knowledge - commodities markets are mostly free of insider-trading restrictions - trading houses have become power brokers, especially in fastdeveloping Asia, Latin America and Africa.” (SCHNEYER, 2011, tradução de livre autoria). 
imensa instabilidade nos preços nas duas pontas. A especulação lucra justamente nesta instabilidade" (DOWBOR, 2018, p. 109).

Em outras palavras, uma vez que as exportaçóes brasileiras são muito dependentes da classe de commodities e a produção é bastante estável, quando há baixa nos preços internacionais, o volume produzido segue constante, mas o produtor passa a ter rendimentos bem menores (DOWBOR, 2018, p. 188). O fato é que não há razóes lógicas, para além da voluntariedade dos intermediários financeiros, para que o preço das commodities tenha tantas variações no mercado internacional (DOWBOR, 2018). É dizer, toda a população sangra para que uma pequena parcela, em sua maioria grupos de intermediadores estrangeiros com sede em paraísos fiscais (DOWBOR, 2018), obtenha lucros cada vez mais expressivos.

$\mathrm{Na}$ definição de Dowbor (2018), o sistema de precificação passa a ser induzido por especulaçóes e não pelos mecanismos tradicionais de oferta e demanda, o que gera distorçóes na economia mundial e impacta a capacidade que os países tem de organizar-se nos âmbitos internos, especialmente desorganizando planejamentos relativos à atividades de produção e de investimentos produtivos.

Ainda que a Teoria Marxista da Dependência, teoria que fundamenta este trabalho, entenda que a única maneira de superar as contradiçóes do sistema capitalista é superando o sistema em si, compreende-se como importante realizar transformaçóes no sistema que abram espaço para mudanças estruturantes posteriores, é dizer "[...] nos interessam medidas que ao introduzir transformaçóes geram espaço para transformações ulteriores" (DOWBOR, 2018, p. 249).

Nesse sentido, Dowbor (2018) assinala uma série de medidas que poderiam ser realizadas para diminuir as distorçôes que se verificam na atualidade; dentre as quais retomar uma regulação sobre o sistema financeiro nacional e a realização de uma reforma tributária se apresentam como propostas urgentes e necessárias, que auxiliariam no combate à desigualdade, mas que demandam um grande esforço e vontade política ${ }^{12}$, justamente porque tocam em privilégios de setores que possuem gigantesco poder político e econômico. O economista também elenca como propostas a redução geral das taxas de juros, a construção de mecanismos que reduzam a evasão fiscal e a necessidade de se ter maior transparência nos fluxos financeiros, uma vez que toda a sociedade é impactada pelo sistema (DOWBOR, 2018).

Ademais, pauta também a necessidade de que seja resgatado o poder regulador do Estado, a fim de que se reduza a possibilidade de que as corporaçóes oligopólicas ditem as regras do jogo (DOWBOR, 2018), o que não se traduz em nenhuma proposta

12 Há de considerar, ainda, a discussão travada no capitulo desde trabalho sobre globalização, Estado e dependência, que demonstra que, na atual fase do capitalismo, os Estados possuem diminuído seu espaço de ação política ante o empoderamento de organismos privados, e que não bata somente a vontade os governantes para que mudanças estruturantes ocorram no plano interno dos países. 
revolucionária ou que demande transformação institucional per si, uma vez que é justamente o que apregoa o artigo 174 da Constituição Federal, ao estabelecer o Estado como agente normativo e regulador da atividade econômica.

Finalmente, o economista pontua que momentos de crise, como o atualmente vivenciado, podem servir como precursores de mudanças, pois “[...] só o aprofundamento das tensóes é que gerará força política capaz de reverter as tendências” (DOWBOR, 2018, p. 276).

\section{Conclusáo}

Para finalizar este estudo cabe destacar que a hipótese inicialmente levantada é confirmada com a pesquisa, pois a dependência econômica nacional segue reproduzida no início do século XXI por meio da política econômica que privilegiou o ciclo das commodities e a operacionalização do sistema financeiro. Isso se dá, principalmente, pelo papel do Estado no cenário de globalização econômica, da concretização da progressiva perda do espaço decisório estatal por meio de reformas constitucionais de caráter neoliberal, ao passo em que organismos e instituiçóes privadas veem seu poder se expandindo e ocupando áreas que até então eram regulamentadas por entes estatais.

Além do mais, se estabelece um vínculo bastante evidente com as preocupaçóes e previsóes dos autores dependentistas no que concerne à reprimarização das economias periféricas e semiperiféricas no mesmo contexto de globalização econômica, que é justamente o que se vislumbra com o exemplo do aumento, no Brasil, da exportação do petróleo como óleo bruto, ao mesmo tempo em que cresce a importação de derivados (AEPET, 2019a; AEPET, 2019b).

Não apenas isso, senão que também se verificam elementos do capitalismo em sua fase financeirizada, uma vez que a política econômica, privilegia a supremacia do capital financeiro sobre o capital produtivo, conforme problematizam os autores referenciados neste trabalho.

O mercado financeiro é extremamente poderoso e incontrolável desde os âmbitos nacionais, e por isso se sugere que a dependência, no contexto atual, se pode denominar globocolonialidade, por se tratar de uma padrão transnacional de poder privado sobre interesses coletivos que recolonizam regióes inteiras sob um padrão de dominação equiparáveis aos padróes do perídio colonial. E mais, esse tipo de dominação assume uma faceta ampla: não só de outros Estados-nação e sociedades é que as sociedades periféricas e semiperiféricas dependem, senão que também circundem à lógicas privadas, do capital financeiro, empresas transnacionais e organismos internacionais privados, cujas instâncias decisórias se encontram distantes das populações que são diretamente afetadas pelas decisóes. 
Com isso, o trabalho objetivou diagnosticar as mudanças ocorridas no cenário globalizado que se vivencia hoje, de modo que seja possível, a partir da realidade concreta de nossa sociedade, buscar delinear como enfrentar tais processos. Trata-se de traçar um horizonte utópico, mas que parta do real, e a partir daí seja palpável pensar em estratégias que possibilitem construir uma nova realidade possível, que passe pela superação da dependência e o rompimento da colonialidade. O que suleou, portanto, toda a investigação foi a preocupação com as condições de vida da população brasileira, que é atravessada por todos os elementos que foram objeto desta investigaçáo: o Estado, a dependência, as commodities, a globalização financeira, etc.

Portanto, a confluência do problema de pesquisa com a hipótese apresentada e os marcos teóricos utilizados na investigação indicam a reprodução da dependência da politica econômica brasileira por meio da política de exportação de commodities, financeirização privatista do capitalismo e desindustrialização. Isto sinaliza para a manutenção da hegemonia da globocolonialidade na atual conjuntura de globalização financeira. Desta forma, torna-se possível sugerir que a globalização que hoje vigora traduz a colonialidade do poder e a dependência a nível global.

\section{Referências}

AEPET - Associação dos Engenheiros da Petrobras. Em 2018, o Brasil exportou 40\% de todo o petróleo cru que produziu. 25 jan. 2019a. Disponível em: . Acesso em: 17 jun. 2019.

AEPET - Associação dos Engenheiros da Petrobras. Em dois anos, refinarias americanas faturam R\$ 37 bilhóes com a venda de diesel ao Brasil. 01 mar. 2019b. Disponível em: . Acesso em: 17 jun. 2019.

BAMBIRRA, Vânia. O capitalismo dependente latino-americano. Florianópolis: Insular, 2015.

BERCOVICI, Gilberto. Teoria do Estado e teoria da Constituição na periferia do capitalismo: breves indagações críticas. In: NUNES, A. J.; COUTINHO, J. N. M. (orgs.). Diálogos Constitucionais: Brasil/Portugal. Rio de Janeiro: Renovar, 2004.

BERCOVICI, Gilberto. Soberania econômica e regime jurídico do capital estrangeiro no Brasil. Revista Brasileira de Estudos Constitucionais - RBEC, Belo Horizonte, ano 5, n.17, p.95-110, jan./mar. 2011.

BERCOVICI, Gilberto. Petrobrás - Monopólio estatal e política concorrencial. Revista Fórum de Direito Financeiro e Econômico, Belo Horizonte, ano 1, no 1 (mar/ago 2012), p. 135-147, 2012. 


\section{BERCOVICI, Gilberto. A Campanha do Petróleo e a Mobilizaçáo Popular em} favor da Petrobrás. 9 fev. 2015. Disponível em: <https:/www.cartamaior.com.br/?/ Editoria/Politica/A-Campanha-do-Petroleo-e-a-Mobilizacao-Popular-em-favor-daPetrobras/4/32839>. Acesso em 18 jun. 2019.

BRASIL. Constituição da República Federativa do Brasil de 1988. Brasília, 1988. Disponível em: <http://www.planalto.gov.br/ccivil_03/constituicao/ constituicaocompilado.htm>. Acesso em 26 mai. 2019.

BRESSER-PEREIRA, Luiz Carlos. Brasil vive desindustrialização. São Paulo: Folha de S. Paulo, 29 ago. 2010. Disponível em: <https://www1.folha.uol.com.br/fsp/mundo/ ft2908201011.htm>. Acesso em 25 mai. 2019.

BUENO, Fábio Marvulle. Presente, passado e futuro do capitalismo brasileiro: o debate da obra de Ruy Mauro Marini. In: SEABRA, Raphael Lana (org). Dependência e marxismo. Contribuiçóes ao debate crítico latino-americano. Florianópolis: Editora Insular, 2017.

CAPUTO LEIVA, Orlando. A economia mundial e a América Latina no início do século XXI. In: SADER, Emir (coord.); DOS SANTOS, Theotônio (coord.); MARTINS, Carlos Eduardo (org.); VALENCIA, Adrián Sotelo (org.). A América Latina e os desafios da globalizaçáo: ensaios dedicados a Ruy Mauro Marini. Rio de Janeiro: Boitempo; PUC-Rio, 2009.

CARDOSO, Fernando Henrique; FALETTO, Enzo. Dependência e desenvolvimento na América Latina: ensaio de interpretação sociológica. 3 ed. Rio de Janeiro: Zahar, 1970.

CARVALHO, Laura. Valsa brasileira: Do boom ao caos econômico. São Paulo: Editora Todavia, 2018.

CARVALHO, Laura. Distribuir renda no Brasil sem mexer nos impostos é quixotesco. São Paulo: El País. 4 jul. 2018b. Entrevista concedida a Felipe Betim e Heloísa Mendonça. Disponível em: <https://brasil.elpais.com/brasil/2018/06/15/ economia/1529091114_614722.html> Acesso em: 12 out. 2018.

DOS SANTOS, Theotônio. A teoria da dependência: balanço e perspectiva. Niterói: [s.n.], 1998. Disponível em: <https://drive.google.com/file/d/0B0eSnYDsJTwR0dXSXZZb2trYjQ/view>. Acesso em: 18 abr. 2018.

DOWBOR, Ladislau. A era do capital improdutivo: a nova arquitetura do poder, sob dominação financeira, sequestro da democracia e destruição do planeta. 2. ed. São Paulo: Autonomia Literária, 2018.

EXAME. Brasil está ainda mais dependente das commodities. São Paulo: Grupo Abril. 10 nov. 2017. Disponível em: <https://exame.abril.com.br/economia/brasil-estaainda-mais-dependente-das-commodities/>. Acesso em: 24 set. 2018. 
FARIA, José Eduardo. O direito na economia globalizada. São Paulo: Malheiros Editores, 2002.

GONZÁLEZ CASANOVA, Pablo. O colonialismo global e a democracia. Rio de Janeiro: Civilização Brasileira, 1995.

GRAU, Eros Roberto. A ordem econômica na Constituição de 1988: interpretação e crítica. 14 ed. São Paulo: Malheiros Editores, 2010.

GUNDER FRANK, Andre. El desarrollo del subdesarrollo. Pensamiento Crítico, Habana, no 7, agosto de 1967.

HERNÁNDEZ CERVANTES, Aleida. La producción jurídica de la globalización económica: notas de una pluralidad jurídica transnacional. Aguascalientes / San Luis Potosí / Ciudad de México: Centro de Estudios Jurídicos y Sociales Mispat / Maestría en Derechos Humanos de la Universidad Autónoma de San Luis Potosí / Centro de Investigaciones Interdisciplinarias en Ciencias y Humanidades de la Universidad Nacional Autónoma de México, 2014.

KATZ, Claudio. La teoria de la dependência, cincuenta ańos despúes. Buenos Aires: Batalla de Ideas, 2018.

MALDONADO-TORRES, Nelson. Sobre la colonialidad del ser: contribuciones al desarrollo de un concepto. Em CASTRO-GÓMEZ, Santiago; GROSFOGUEL, Ramon (coords.) El giro decolonial: reflexiones para uma diversidad epistêmica más allá del capitalismo global. Bogotá: Siglo del Hombre Editores; Universidad Central, Instituto de Estudios Sociales Contemporáneos, Pontificia Universidad Javeriana, Instituto Pensar, 2007, p. 127-167.

MARINI, Ruy Mauro. Dialética da dependência. Ensaio datado de 1973. Tradução: Marcelo Carcanholo. Post-scriptum traduzido por Carlos Eduardo Martins. Fonte: Editora Era, México, 1990, 10a edição (1a edição, 1973). Post-scriptum conforme: Revista Latinoamericana de Ciências Sociales, Flacso, (Santiago de Chile), n 5, junho 1973. Versão digitalizada conforme publicado em "Ruy Mauro Marini: Vida e Obra", Editora Expressão Popular, 2005.

MARINI, Ruy Mauro. Subdesenvolvimento e Revolução. Coleção Pátria Grande. Florianópolis: Insular, 2012.

MARINI, Ruy Mauro. América Latina, dependencia y globalización. México, D. F: Siglo XXI Editores; Buenos Aires: CLACSO, 2015.

MARTINS, Carlos Eduardo. Globalização, dependência e neoliberalismo na América Latina. São Paulo: Boitempo, 2011.

OLIVEIRA, Francisco de. Brasil: uma biografia não autorizada. São Paulo: Boitempo, 2018. 
ONU Brasil. Aumenta peso das commodities para economia do Brasil, revela relatório da ONU. [s.l.]. 10 nov. 2017. Disponível em: <https://nacoesunidas.org/ aumenta-peso-das-commodities-para-economia-do-brasil-revela-relatorio-da-onu>. Acesso em: 24 set. 2018.

OURIQUES, Nildo Domingo. Por uma teoria marxista da dependência. In: SEABRA, Raphael Lana (org). Dependência e marxismo. Contribuições ao debate crítico latinoamericano. Florianópolis: Editora Insular, 2017.

PORTO-GONÇALVES, Carlos Walter. Apresentação da edição em português. In: LANDER, Edgard (org). A colonialidade do saber: eurocentrismo e ciencias sociais. Perspectivas latinoamericanas. Colección Sur Sur. Buenos Aires: CLACSO, 2005.

PUCEIRO, Enrique Zuleta. O processo de globalização e a reforma do Estado. In: FARIA, José Eduardo (org.). Direito e globalizaçáo econômica: implicações e perspectivas. São Paulo: Malheiros Editores, 2010.

QUIJANO, Anibal. La modernidad, el capital y América Latina nacen el mismo día. Entrevista concedida à Nora Velarde. ILLA - Revista del Centro de Educación y Cultura, n. 10, p. 42-57, 1991.

QUIJANO, Anibal. Colonialidad y modernidad/racionalidad. Perú indígena, v. 13, n. 29, p. 11-20, 1992.

QUIJANO, Anibal. Colonialidade do poder, eurocentrismo e América Latina. In: LANDER, Edgard (org). A colonialidade do saber: eurocentrismo e ciencias sociais. Perspectivas latinoamericanas. Colección Sur Sur. Buenos Aires: CLACSO, 2005.

SCHNEYER, Joshua. Commodity Traders: The trillion dollar club. Estados Unidos: Reuters, 2011. Disponível em: <https://www.reuters.com/article/ us-commodities-houses/corrected-commodity-traders-the-trillion-dollar-clubidUSTRE79R4S320111028>. Acesso em 26 mai. 2019.

SOTELO VALENCIA, Adrián. América Latina: de crisis y paradigmas. La teoría de la dependencia en el siglo XXI. México, D.F.: Plaza y Valdés, 2005.

SOTELO VALENCIA, Adrián. Neo-imperialismo, dependência e novas periferias na economia mundial. In: SADER, Emir (coord.); DOS SANTOS, Theotônio (coord.); MARTINS, Carlos Eduardo (org.); VALENCIA, Adrián Sotelo (org.). A América Latina e os desafios da globalização: ensaios dedicados a Ruy Mauro Marini. Rio de Janeiro: Boitempo; PUC-Rio, 2009.

SOUZA, Jessé. A elite do atraso: da escravidão à Lava Jato. Rio de Janeiro: Leya, 2017.

SVAMPA, Maristella. Consenso de los commodities, giro ecoterritorial y pensamiento crítico en América Latina. In: Movimientos socioambientales en América Latina. 
Revista del Observatorio Social de América Latina, año XIII, no 32 . Buenos Aires: CLACSO, outubro de 2012.

SVAMPA, Maristella. «Consenso de los Commodities» y lenguajes de valoración en América Latina. Revista Nueva Sociedad, n. 244, p. 30-46, março-abril de 2013.

UNCTAD. Conferência das Naçóes Unidas sobre o Comércio e Desenvolvimento. State of Commodities Dependence - 2016. 2017. Disponível em: <http://unctad.org/ en/PublicationsLibrary/suc2017d2.pdf>. Acesso: 24 set. 2018. 